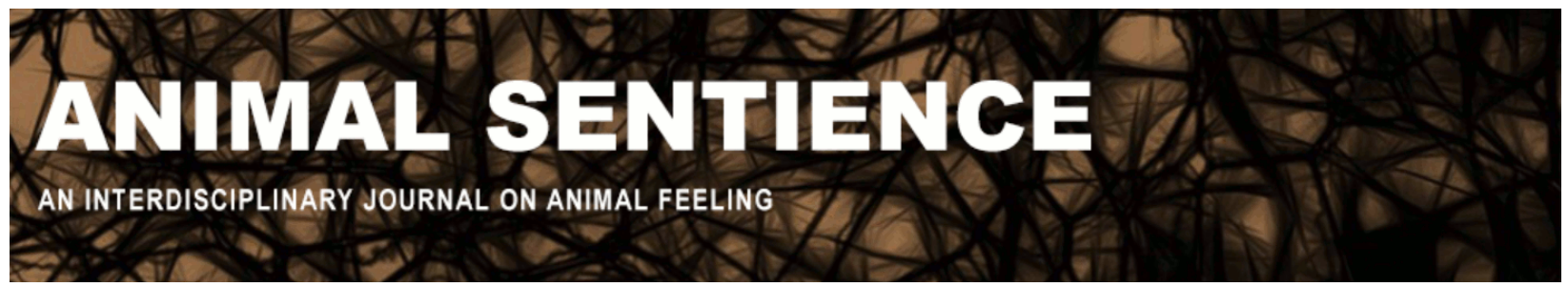

Johannsen, Kyle (2016) Animal welfare at home and in the wild. Animal Sentience 7(10)

DOI: $10.51291 / 2377-7478.1088$

Date of submission: 2016-02-13

Date of acceptance: 2016-03-01

(c)

This article has appeared in the journal Animal

Sentience, a peer-reviewed journal on animal

cognition and feeling. It has been made open access,

free for all, by WellBeing International and deposited

in the WBI Studies Repository. For more information,

please contact

wbisr-info@wellbeingintl.org.

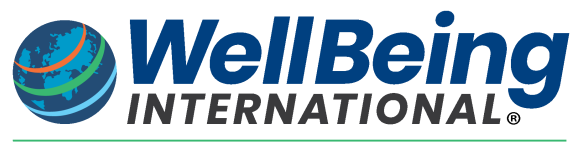

SOLUTIONS FOR PEOPLE, ANIMALS AND ENVIRONMENT 


\title{
Animal welfare at home and in the wild
}

Commentary on $\mathrm{Ng}$ on Animal Suffering

\author{
Kyle Johannsen \\ Department of Philosophy \\ Trent University
}

\begin{abstract}
In recent work, economist Yew-Kwang Ng suggests strategies for improving animal welfare within the confines of institutions such as the meat industry. Although I argue that $\mathrm{Ng}$ is wrong not to advocate abolition, I do find his position concerning wild animals to be compelling. Anyone who takes the interests of animals seriously should also accept a cautious commitment to intervention in the wild.
\end{abstract}

Kyle Johannsen 9kj29@queensu.ca
is an instructor of Philosophy at
Trent University. His research is in
social and political philosophy,
especially distributive justice, and in
applied ethics, especially animal
ethics. https://queensu.academia.edu/KyleJohannsen

In recent work, economist Yew-Kwang Ng (2016) suggests a number of strategies for improving animal welfare. For the most part, his recommendations consist of low-cost, relatively easy to implement strategies that would reduce the suffering of animals - specifically domesticated animals - without actually challenging the institutions of animal agriculture or animal ownership. In other words, Ng adopts an animal welfarist position, rather than a liberationist one. Examples of his welfarist suggestions include increasing the minimum legal size of chicken cages and outlawing cruel practices such as the use of whips in horse racing. In addition, $\mathrm{Ng}$ argues that animal welfare advocates will be more effective if, among other things, they focus on improving the welfare of farmed animals rather than wild animals. He suggests that since we have more contact with farmed animals and are directly responsible for the harms befalling them, it will be easier to convince people to help them than to help wild animals. He also claims that attempting to assist wild animals may have unexpected ecological consequences.

Thus far, commentators have been critical of both $\mathrm{Ng}^{\prime}$ s welfarism and his stance on wild animals. With respect to their criticisms of welfarism in particular, I am broadly sympathetic. ${ }^{1}$ In fact, it seems to me that $\mathrm{Ng}$, as a self-proclaimed utilitarian - that is, someone who thinks right

\footnotetext{
${ }^{1}$ For their criticisms of animal welfarism, see Baker (2016); Bekoff and Pierce (2016); Leadbeater (2016); Marino (2016); and Marks (2016).
} 
action requires the maximization of welfare across individuals ${ }^{2}-$ should himself reject animal welfarism. ${ }^{3}$ Although utilitarians and animal welfarists have in common their concern for the reduction of suffering, there are important differences between them. For most utilitarians (at least the consistent ones), whether a being has moral status is determined by whether that being has subjective interests, that is, whether it feels pain and pleasure and has preferences. As such, utilitarians reject the view that the advanced cognitive abilities most animals lack, for example, the ability to engage in moral dialogue and critical moral reflection, are prerequisites for full moral standing. Animal welfarists, by contrast, tend to hold the view that such cognitive abilities are necessary for full moral standing. Though they accord some moral significance to the interests of animals, that significance is low enough to be defeated by even trivial human interests, for example, whatever interest human beings have in continuing to eat foods they have grown accustomed to. It seems to me that if $\mathrm{Ng}$ accepts Jonathan Balcombe's $(2010, \mathrm{p} .44)$ claim that the condition on which the applicability of moral concern depends "is not a capacity to think, but a capacity to feel" (i.e., sentience), then $\mathrm{Ng}$ should also accept that breeding and slaughtering animals for the sake of a trivial human interest is a practice that must be abolished, at least in the long run.

With respect to wild animals, however, I think $\mathrm{Ng}^{\prime}$ s position is quite compelling. Before I explain why, however, some clarification is in order. When $\mathrm{Ng}$ claims that our current focus should be on improving the welfare of farmed animals rather than wild animals, he isn't claiming that we should ignore the negative impact that human actions are having on wild animals' habitats. ${ }^{4}$ In fact, $\mathrm{Ng}$ notes that with respect to human-caused damage to habitats, our relationship with wild animals is similar to our relationship with domesticated animals in that human behavior is responsible for the harms befalling them. What $\mathrm{Ng}$ is expressing caution about is large-scale interventions that aim at reducing the total amount of suffering in the wild, irrespective of its causes. He thinks that intervening in natural processes such as the predator-prey relationship or wild animal reproduction is desirable in theory, but that it is also ecologically dangerous. On his view, we should refrain from large-scale interventions at present, but we should also be conducting the research needed to bring the risks of intervention down to an acceptable level. ${ }^{5}$

Understood in the above manner, I don't think many animal rights theorists would criticize $\mathrm{Ng}$ for being inattentive to the interests of wild animals. Quite the opposite: many would claim that he's taking his concern for wild animals' welfare too far. The prevalent view among animal rights theorists is that we should, for the most part, leave wild animals alone. Though we have a duty to refrain from hunting and other actions that cause harm, we do not, according to this view,

\footnotetext{
${ }^{2}$ My description of utilitarianism is, I hope, neutral with respect to the theory's many variations. Utilitarians disagree about many things, including whether we should be concerned with average and not aggregate welfare, expected rather than achieved welfare, etc.

${ }^{3}$ For his thoughts about utilitarianism, see $\mathrm{Ng}$ (2000).

${ }^{4}$ See Leadbeater (2016). For other commentaries where $\mathrm{Ng}$ is criticized for being insufficiently mindful of the welfare of wild animals, see Baker (2016) and Marino (2016).

${ }^{5}$ For an interview during which $\mathrm{Ng}$ discusses his views about wild animals, see Carpendale (2015). For the influential article around which much of the interview is focused, see $\mathrm{Ng}$ (1995).
} 
have a duty to prevent natural harms such as death by starvation, predation, exposure, etc. (Regan 1983, p. 357; Singer 1975, pp. 238-239; Marks 2016).

With respect to the matter of wild animals, however, I think it is $\mathrm{Ng}$ who has the more consistent position. Just as $\mathrm{Ng}$ should acknowledge that we ought to be working towards abolishing institutions such as the meat industry, ${ }^{6}$ animal rights theorists should acknowledge that their position also requires a hypothetical commitment to intervening in the wild, that is, a commitment to intervening in the event that it becomes ecologically safe to do so. Though human-caused harms such as habitat destruction are morally different from naturally occurring harms, the difference between them is not so great as to justify the claim that we have reason to care only about the former and not about the latter. Our duties to avoid harming others are especially stringent, but we also owe duties of assistance to those in need when we can help them without excessive cost to ourselves or to others. In light of this, a number of authors working on issues in animal ethics have accepted that intervening to reduce the amount of suffering in nature is morally desirable, so long as we recognize our current lack of knowledge as a constraint on our ambitions (McMahan 2010; Horta 2013, 2015; Tomasik 2015). I think Ng should be commended for his progressive and yet cautious stance towards suffering in the wild, a topic that has only recently begun to attract much philosophical attention.

\section{References}

Baker, L. (2016). What's the common sense of just some improvement of some welfare for some animals? Animal Sentience 2016.068.

Balcombe, J. (2010). Second nature. New York: Palgrave Macmillan.

Bekoff, M. and Pierce, J. (2016). Animal welfare cannot adequately protect nonhuman animals: The need for a science of animal well-being. Animal Sentience 2016.067.

Carpendale, M. (2015). Welfare biology as an extension of biology: Interview with Yew-Kwang Ng. Relations, 3, 133-152.

Donaldson, S. and Kymlicka, W. (2011). Zoopolis: A political theory of animal rights. New York: Oxford University Press.

Horta, O. (2013). Zoopolis, intervention, and the state of nature. Law, Ethics, and Philosophy, 1, 113-25.

Horta, O. (2015). The problem of evil in nature: Evolutionary bases of the prevalence of disvalue. Relations, 3, 17-32.

\footnotetext{
${ }^{6}$ Though the meat industry should certainly be abolished, I think it's important to note that it is possible to socially cooperate with domesticated animals in a morally acceptable manner. For work exploring this possibility, see Donaldson and Kymlicka (2011).
} 
Leadbeater, S. R. B. (2016). Animal suffering calls for more than a bigger cage. Animal Sentience 2016.071.

Marino, L. (2016). Why animal welfarism continues to fail. Animal Sentience 2016.074.

Marks, J. (2016). End-state welfarism. Animal Sentience 2016.075.

McMahan, J. (2010). The meat eaters. New York Times Opinionator.

$\mathrm{Ng}$, Y-K. (1995). Towards welfare biology: Evolutionary economics of animal consciousness and suffering. Biology and Philosophy, 10, 255-285.

$\mathrm{Ng}$, Y-K. (2000). Efficiency, equality, and public policy: With a case for higher public spending. London: Macmillan.

Ng, Y-K. (2016). How welfare biology and commonsense may help to reduce animal suffering. Animal Sentience 2016.007.

Regan, T. (1983). The case for animal rights. Berkeley: University of California Press.

Singer, P. (1975). Animal liberation. New York: Avon Books.

Tomasik, B. (2015). The importance of wild animal suffering. Relations, 3, 133-152. 